\title{
GREENHOUSE GAS EMISSIONS AND ENERGY SAVINGS OWING TO WATER APPLIANCES RETROFIT
}

\author{
RITA POMBO ${ }^{1}$, VITOR SOUSA ${ }^{2} \&$ INÊS MEIRELES ${ }^{1}$ \\ ${ }^{1}$ RISCO, University of Aveiro, Portugal \\ ${ }^{2}$ IST, University of Lisbon, Portugal
}

\begin{abstract}
Amongst the various global environmental threats, fresh water shortages and pollution are two of the most critical issues. In this regard, efficient use of water inside buildings is a priority in the broad scope of sustainability to a large extent due to the water-energy connection. Despite the various technological improvements in equipment and appliances, whenever the water efficiency is directly related to the individual's direct consumption their performance will be affected by comfort perception and behaviour change. This paper aims to evaluate the effects of using different individual domestic water appliances on greenhouse gas emissions considering the urban water cycle. The flow reduction associated with the installation of these appliances is reflected not only in water savings at the building level, but also in lower energy consumption required to transport and treat water and wastewater. This contributes to the reduction of carbon emissions, resulting in broader positive environmental impacts. The Department of Civil Engineering of the University of Aveiro is used as a case study. Water consumption throughout the year is available from the metering system and in-situ campaigns were carried out to characterize the water end-use pattern and the effective water consumption reduction due to the installation of tap aerators. Operational energy consumption in water supply and wastewater drainage systems were obtained from the water utility and the carbon emissions from electrical energy production were obtained from the energy supplier.
\end{abstract}

Keywords: water-efficiency, energy, greenhouse gas emissions.

\section{INTRODUCTION}

Nowadays, sustainability is one of the greatest challenges and is becoming a key goal in virtually all human endeavours. The integration of the economic, ethical and environmental values encompassed in the notion of sustainability has its roots in the latter. In fact, the emergence of the concept of sustainable development started with the consciousness regarding the environmental impacts as a result of the human activities. Additionally, the observation of the complexity of the global interaction between all the components and aspects pertaining to the natural ecosystem to achieve a balance state and how these are affected by and affect humans, evidenced the need to account for the relevant connections.

Water, being a key resource indispensable for life as we know, has been related to energy for a long period. The interaction between water as both a source and a consumer of energy has been explored under the designation of water-energy nexus (e.g. DOE [1]). More recently, the idea expanded to the water-energy-food nexus (e.g. Flammini et al. [2]), motivated by the population growth and the exploitation of alternative vegetable fuels, or the water-energy-emissions nexus (e.g. Chhipi-Shrestha et al. [3]), motivated by evidence of climate changes.

Pertaining to sustainable construction, the present communication aims at quantifying the water-energy-emissions nexus in buildings. The scope is limited to the water consumption during the operation stage of a building life cycle, particularly in the toilet facilities, using the Department of Civil Engineering (DECivil) building at the University of Aveiro, Portugal, as a case study. 


\section{METHODOLOGY}

An analytical approach is adopted in the present study to link water consumption with energy consumption and $\mathrm{CO}_{2}$ emissions. The methodology encompasses three main steps to allow linking the referred elements:

- Estimate the water consumption reduction potential through the implementation of water efficient measures;

- Determine the energy consumption in the urban water cycle and, if applicable, in the building per unit volume of water;

- Evaluate the gas emissions from energy production.

The first step is to characterise the existing situation, which requires the knowledge of the existing equipment and fixtures discharge and their use patterns to estimate the corresponding contribution for the total water consumption. Identifying possible water efficient measures and assessing their effective performance in terms of water consumption reduction will enable estimating the water consumption savings potential for each specific water end-use and water efficient alternative solution.

The urban water cycle is divided into water supply and wastewater drainage. Water supply requires energy for abstracting, treating, and distributing potable water that depends on: i) the water source types (e.g., groundwater, surface water) and characteristics (e.g., water quality); ii) the consumption requirements and its spatial distribution; iii) the relative location of the water consumers to the water sources and the land topography; and iv) the system configuration, technology and energy performance. Similarly, energy is also required for the drainage, treatment and disposal of wastewater. The amount of energy required for wastewater will depend on factors similar to those needed for water supply, replacing the water source by the final destination of the treated wastewater.

Sometimes, due to the building characteristics, water use may require additional energy consumption at a building level. Most common situation is energy consumption for pumping when the public water supply is not compatible with the building height of pressure requirements for specific uses. Some cases may even demand additional water treatment for very sensible water uses.

The gas emissions will depend on the source of energy used in the urban water cycle and building water related to energy consumption. The energy source may, in turn, have an energy mix that drives the gas emissions.

\section{CASE STUDY}

\subsection{Framework}

The DECivil building is located in the Campus Universitario de Santiago, Aveiro - Portugal (Fig. 1). Built in 2004, the building has a rectangular shape and 3 floors. The ground floor is mainly occupied by laboratories, with roughly half of it with two stories high extending to the first floor. The remaining of the first floor area is composed by classrooms. The higher floor is split into offices and classrooms.

The building is used by approximately 300 individuals, mostly students, but also researchers, professors and administrative and lab workers. Being a university building, its community and dynamics vary significantly with time. At an annual scale, the academic calendar is divided into classes, exams, dissertations discussion, interruptions and vacations periods, which drive the building occupancy rate. 


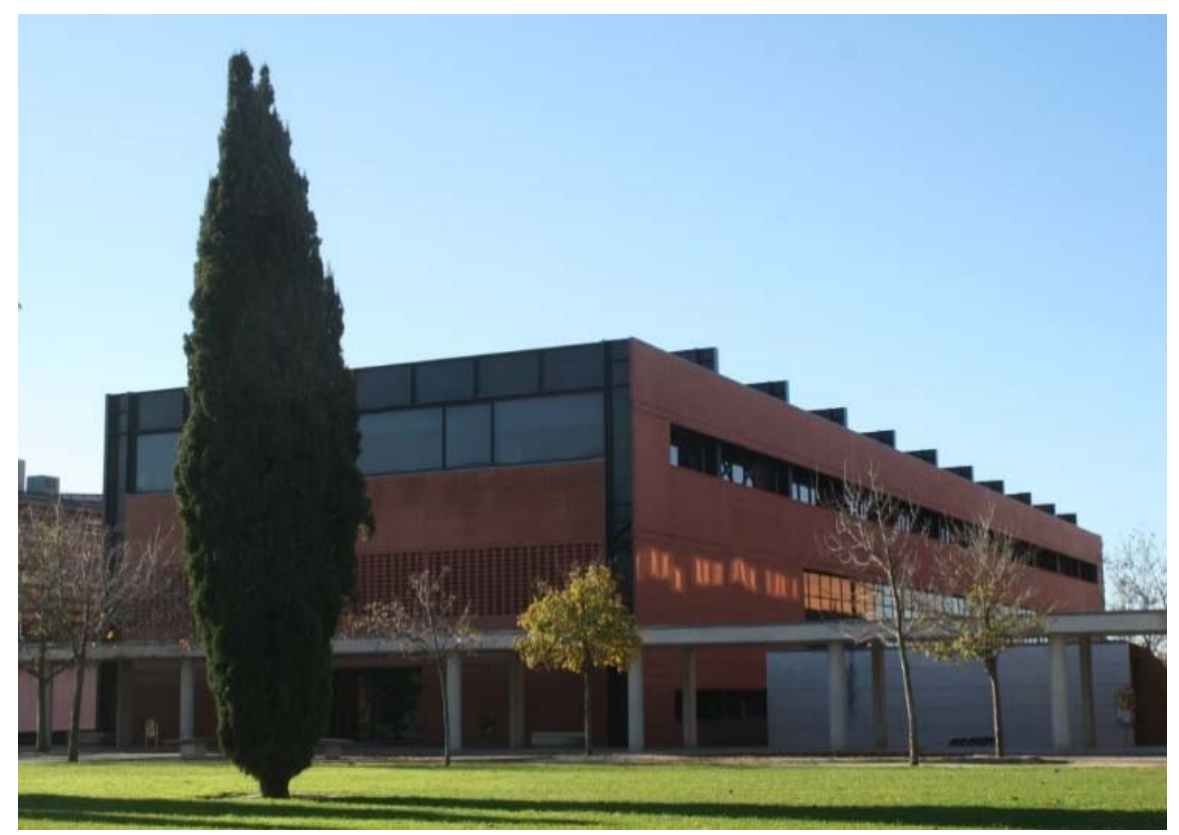

Figure 1: View of the DECivil building.

At an interannual scale, the users and their number change with the rate of new students' arrivals and the rate of students concluding their degree.

Water consumption in the building is related to the use of the toilet facilities and the laboratories and due to cleaning operations. Previous studies [4], [5] found that, on average, $70 \%$ of the water is consumed in the toilet facilities and the remaining $30 \%$ in the laboratories and cleaning operations. The later contributes marginally for the overall water consumption in the DECivil building and the water consumption in laboratorial activities is usually volume driven rather than discharge driven, therefore, only possible to change through the use of alternative water sources.

Within this context, the highest water efficiency potential in the DECivil lies on the use of water efficient appliances in the toilet facilities. There are six toilet facilities, 3 for male users and 3 for female users, totalling 14 washbasins, 11 flush toilets and 10 urinals (Table 1).

Table 1: Water fixtures per toilet facility.

\begin{tabular}{|l|c|c|c|c|}
\hline Toilet facilities & Floor & Washbasin & Flush toilet & Urinal \\
\hline Male users & 1 & 2 & 2 & 4 \\
MT1 & 2 & 3 & 2 & 3 \\
MT2 & 2 & 2 & 1 & 3 \\
MT3 & 1 & 3 & 2 & - \\
\hline Female users & 2 & 2 & 2 & - \\
FT1 & 2 & 2 & - \\
FT2 & 2 & & \\
FT3 & & & & \\
\hline
\end{tabular}




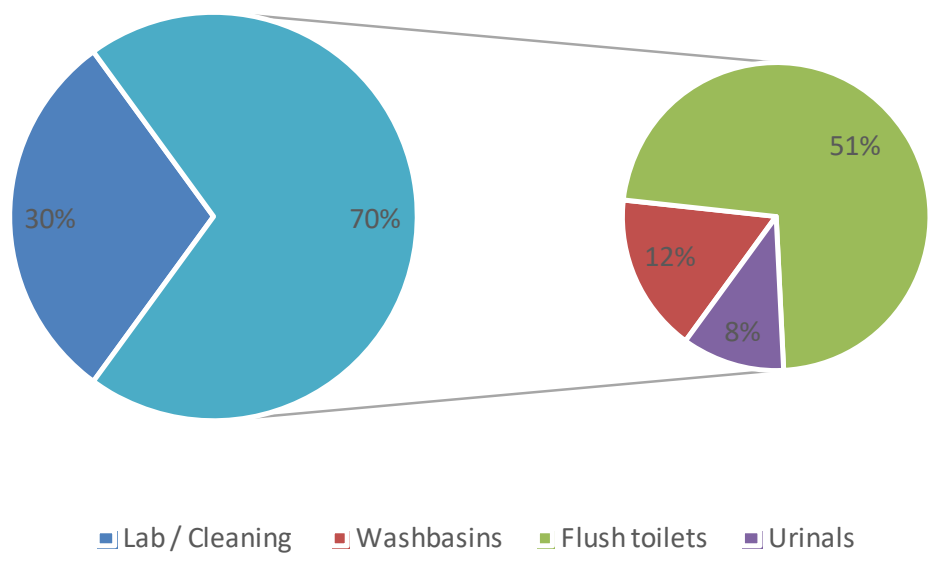

Figure 2: Water end-use distribution in the DECivil building.

Meireles et al. [5] also found that, in the toilet facilities, $72 \%$ of the water consumption is used in the flush toilets, $17 \%$ in the washbasins and $11 \%$ in the urinals. The resulting water end-use distribution in the DECivil building is presented in Fig. 2.

\subsection{Water consumption reduction potential}

The water efficiency measures identified to assess were: i) water reduced for the taps; ii) dual flush water efficient toilets; and iii) waterless urinals. The water reducers efficiency will depend on the users' behaviour. Meireles et al. [6] found that reduction in water consumption associated to the installation of water reducers in the DECivil building was lower than the reduction of water discharge due to user's behaviour adjustment to the lower water discharge (no change in the duration of operation per push was introduced).

The efficiency due to the use of dual flush toilets will depend on both the discharge reduction and the proportion of full and reduced discharge uses. In the present study was considered a proportion of 3 reduced discharges per full discharge, as considered by the European Water Label. Waterless urinals eliminate the need for water. Their effective efficiency in the overall consumption at the male user's toilet facilities will still depend on the proportion use of the flush toilets and the urinals. In the DECivil building, the use frequency of flush toilets and urinals is considered unchanged.

The water discharge performance of the existing features and selected water efficient alternatives are presented in Tables 2 and 3 .

Table 2: Characteristics of the base situation appliances.

\begin{tabular}{|l|c|c|l|l|}
\hline \multicolumn{1}{|c|}{ Appliances } & $\begin{array}{c}\text { Discharge } \\
(\mathbf{l} / \mathbf{m i n})\end{array}$ & $\begin{array}{c}\text { Volume per use } \\
(\mathbf{l})\end{array}$ & \multicolumn{1}{|c|}{ Type } & Operation \\
\hline Washbasin taps & 6.7 & $0.85^{*}$ & Manual push & Fixed time \\
\hline Flush toilets & - & 7.24 & Manual push & Fixed volume \\
\hline Urinals & 15 & 1.53 & Manual push & Fixed time \\
\hline
\end{tabular}

*The volume per use accounts for users pushing more than once. 
Table 3: Characteristics of the water efficient appliances.

\begin{tabular}{|l|c|c|l|l|}
\hline \multicolumn{1}{|c|}{ Appliances } & $\begin{array}{c}\text { Discharge } \\
(\mathbf{l} / \mathbf{m i n})\end{array}$ & $\begin{array}{c}\text { Volume per use } \\
\text { (l) }\end{array}$ & \multicolumn{1}{|c|}{ Type } & Operation \\
\hline Washbasin taps & 2.0 & $0.43^{*}$ & Manual push & Fixed time \\
\hline Flush toilets & - & $3.75(\mathrm{PT})$ & Manual push & Fixed volume \\
\hline Urinals & 0 & $2.95(\mathrm{EU})$ & & \\
\hline
\end{tabular}

*The volume per use accounts for users pushing more than once and the adjustment on number of pushes by the users.

\subsection{Water related energy consumption}

In Portugal, energy consumption in water supply services ranged from $0.001 \mathrm{kWh} / \mathrm{m}^{3}$ to $4.77 \mathrm{kWh} / \mathrm{m}^{3}$, with an average of $0.45 \mathrm{kWh} / \mathrm{m}^{3}$, and in wastewater drainage from $0.0001 \mathrm{kWh} / \mathrm{m}^{3}$ to $1.62 \mathrm{kWh} / \mathrm{m}^{3}$, with an average of $0.24 \mathrm{kWh} / \mathrm{m}^{3}$. Figs 3 and 4 present the histograms of energy consumption from the 263 and 266 water and wastewater utilities operating in Portugal in 2015.

Since the water market in Portugal is divided into "bulk" (water abstraction and treatment and wastewater treatment and disposal) and "retail" (water distribution and wastewater collection) segments, the total energy consumption in the urban water cycle must take into account the various components involved. In practice, there is no rigid split between bulk and retail service, with some bulk utilities also supplying water or collecting wastewater directly to or from final consumers and some retail utilities abstracting and treating part of the water supplied or treating and discharging part of the wastewater.

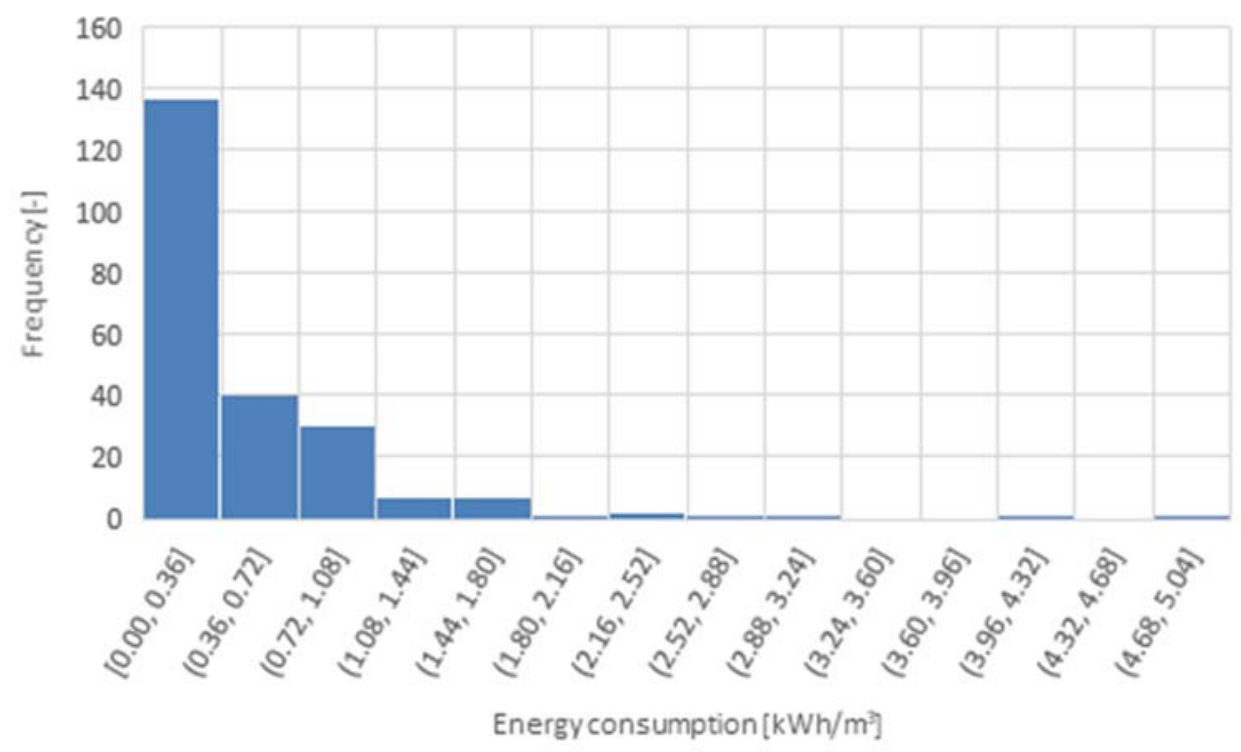

Figure 3: Water energy consumption in 2015. 


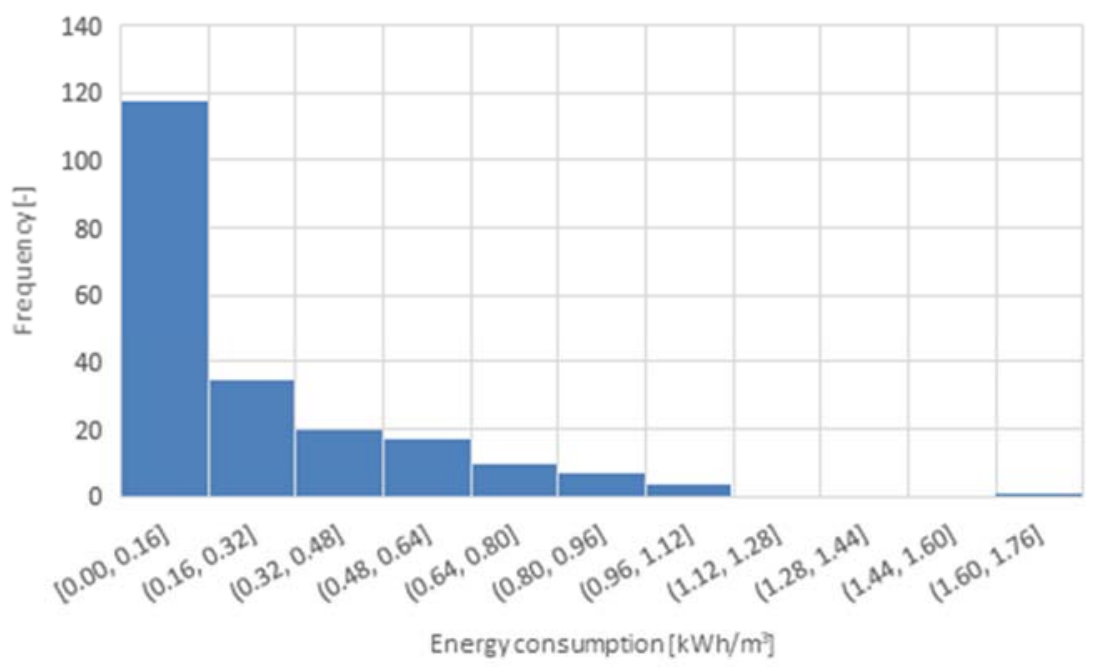

Figure 4: Wastewater energy consumption in 2015.

For the majority of the water and wastewater systems in Portugal, the energy consumed in the bulk segment has to be added to the energy consumed in the retail segment to obtain the total energy consumption in the urban water cycle. Figs 5, 6 and 7 present the energy consumption in bulk and retail segments for water and wastewater.

In Aveiro, the total energy consumption in 2015 , considering both the bulk and retail markets, was of $0.76 \mathrm{kWh} / \mathrm{m}^{3}$ for the water service and of $0.36 \mathrm{kWh} / \mathrm{m}^{3}$ for the wastewater service, totalling $1.12 \mathrm{kWh} / \mathrm{m}^{3}$ for the urban water cycle. Since the infrastructures and the energy efficiency evolve very slowly, the total energy consumption may vary throughout the years with the differences in the volume of water supplied/drained, but the energy spent per cubic meter has remained constant in the last years.
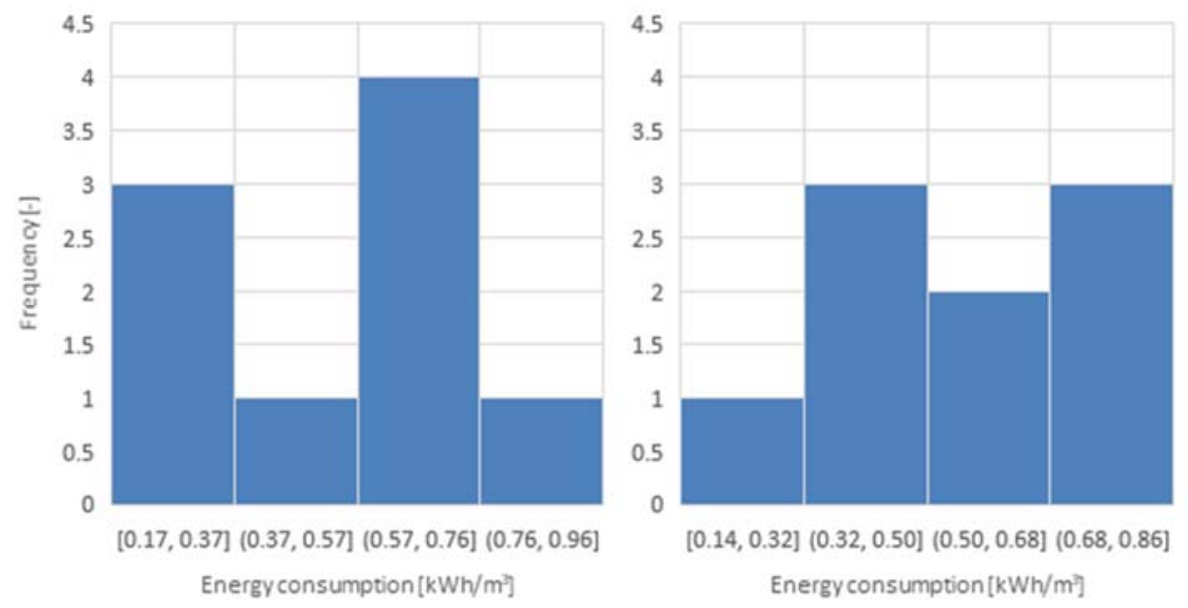

Figure 5: Water (left) and wastewater (right) bulk services energy consumption in 2015. 


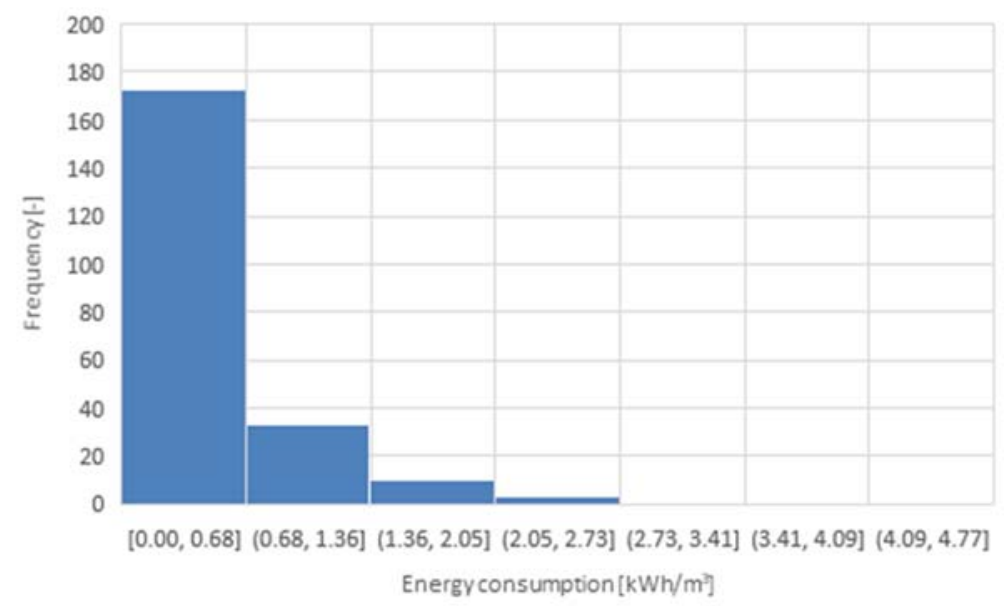

Figure 6: Water retail services energy consumption in 2015.

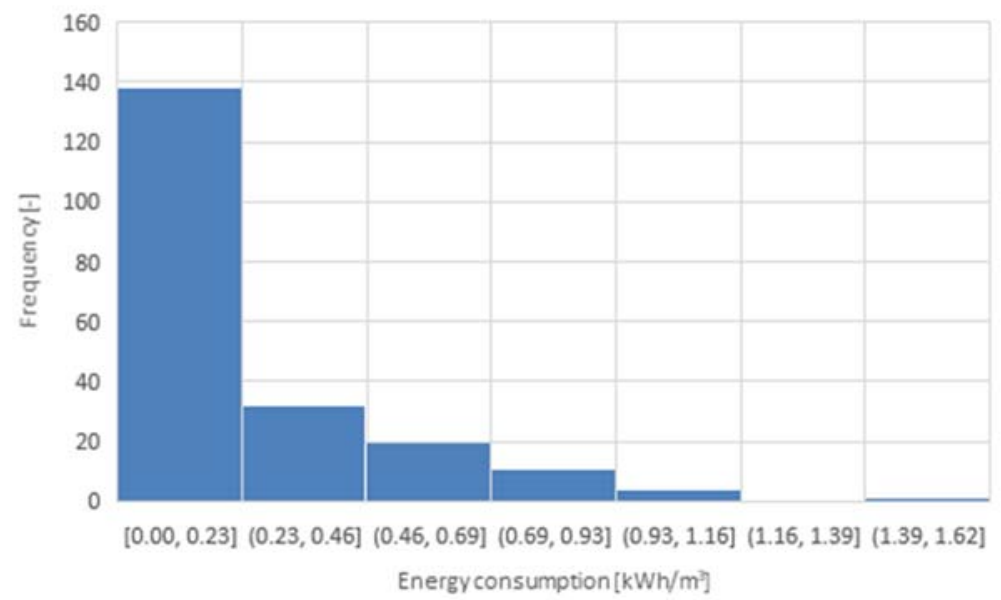

Figure 7: Wastewater retail services energy consumption in 2015.

\subsection{Energy related $\mathrm{CO}_{2}$ emissions}

The energy consumed in the urban water cycle is $100 \%$ from the electrical network. EDP Energias de Portugal, being the electricity market leader in Portugal, was selected has the reference energy supplier.

EDP generates electricity through different technologies and primary energy sources that can be renewable or non-renewable (also called traditional sources). Electricity from traditional sources is produced by burning fossil fuels (coal and natural gas) in nuclear 
reactors (imported) and through cogeneration. Water, wind and sun are the more common renewable generation sources.

The energy mix is constantly changing due to weather conditions and the evolution of the installed power proportion of the various energy sources (Fig. 8), resulting in $\mathrm{CO}_{2}$ emissions differences. For the purpose of the present study, the year 2015 was adopted as the reference year, corresponding to $192 \mathrm{~g}$ of $\mathrm{CO}_{2} / \mathrm{kWh}$.

\section{RESULTS AND DISCUSSION}

Disregarding the monthly variations in energy mix and water consumption and considering the year of 2015 as a reference year, the potential annual water savings are of $234.1 \mathrm{~m}^{3}$, considering the PT flush toilets, or $269 \mathrm{~m}^{3}$, considering the EU flush toilets. This would enable saving $105.4 \mathrm{kWh}(\mathrm{PT})$ or $121.1 \mathrm{kWh}(\mathrm{EU})$ in Aveiro, which corresponds to a reduction of $18830 \mathrm{gCO}_{2}$ or $21630 \mathrm{gCO}_{2}$ with $\mathrm{EDP}$ as the energy provider.

The distribution of the potential water savings and corresponding energy savings and emissions reductions by the various water efficient appliances are presented in Table 4.

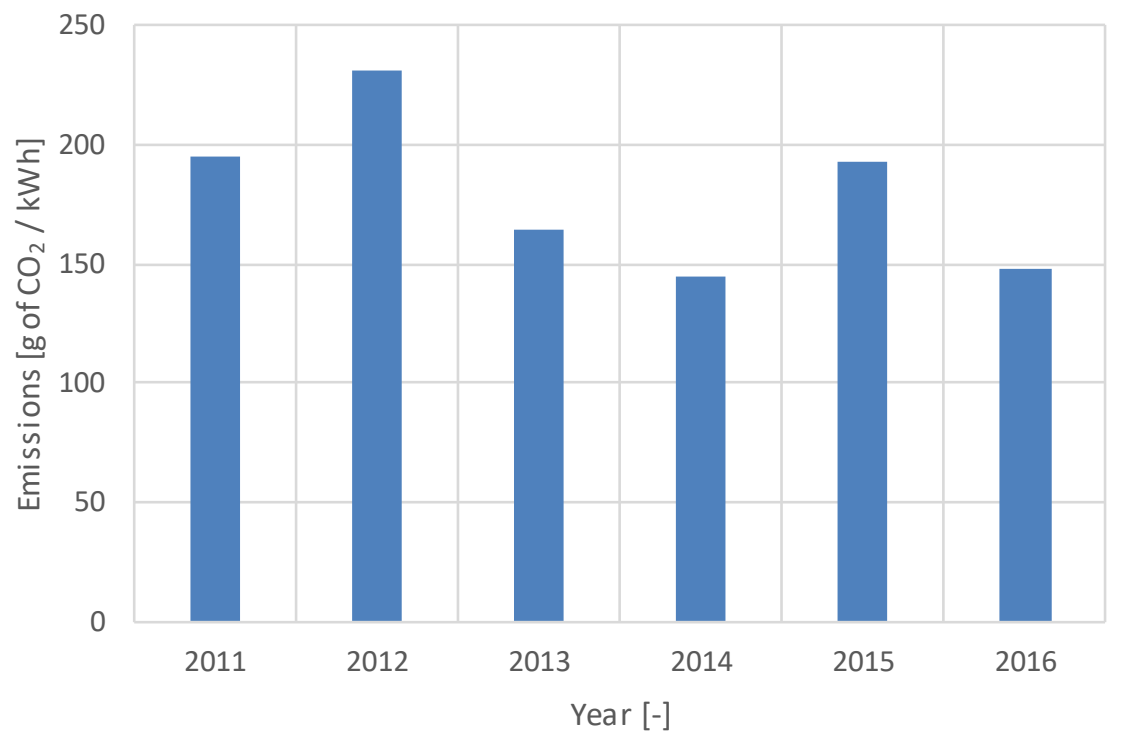

Figure 8: $\mathrm{EDP} \mathrm{CO}_{2}$ emissions for electricity production.

Table 4: Contribution of each water efficient appliance to the reduction in water and energy consumption and $\mathrm{CO}_{2}$ emissions.

\begin{tabular}{|l|c|c|c|}
\hline \multicolumn{1}{|c|}{ Appliances } & $\begin{array}{c}\text { Water savings } \\
\left(\mathbf{m}^{\mathbf{3}} \mathbf{)}\right.\end{array}$ & $\begin{array}{c}\text { Energy savings } \\
\mathbf{( k W h )}\end{array}$ & $\begin{array}{c}\text { Emissions reduction } \\
\mathbf{( g C O 2})\end{array}$ \\
\hline Washbasin taps & 35.4 & 15.9 & 2,847 \\
\hline \multirow{2}{*}{ Flush toilets } & $151.8(\mathrm{PT})$ & $68.3(\mathrm{PT})$ & $12,205(\mathrm{PT})$ \\
& $186.6(\mathrm{EU})$ & $84.0(\mathrm{EU})$ & $15,004(\mathrm{EU})$ \\
\hline Urinals & 47.0 & 21.1 & 3,778 \\
\hline
\end{tabular}




\section{CONCLUSIONS}

The present research explores the water-energy-emissions nexus in a Mediterranean context. Using the DECivil building as a case study and considering the regional context in terms of the urban water cycle and the energy mix used.

The results contribute to demonstrate that, from a sustainability context, the existing links widen the true benefits from water efficiency. Considering that the case study has a water consumption pattern quite distinct from residential use and does not have hot water consumption, the potential benefits from water efficient appliances retrofit in residential buildings, where most of the urban water consumption takes place, are even higher.

\section{ACKNOWLEDGEMENTS}

This study was performed in the framework of the R\&TD Co-Promotion Project "MoBaK Modular Bathroom Kit/Oliveira \& Irmão S.A.”, n 17719, 33/SI/2015 - R\&D Enterprise (cofunded), supported by Portugal and the European Union through the FEDER, COMPETE 2020 and Centro 2020, under Portugal 2020, through which RP is being supported (Research Fellowship BI/UI99/7734/2017). IM acknowledges the support from FCT through the Sabbatical Leave Fellowship SFRH/BSAB/135243/2017 for her stay at the University of Bath, during which part of the analysis was carried out. The authors would also like to acknowledge AdRA and EDP for providing data.

\section{REFERENCES}

[1] DOE, The Water-Energy Nexus: Challenges and Opportunities, U.S. Department of Energy, 2014. DOE/EPSA-0002.

[2] Flammini, A., Puri, M., Pluschke, L. \& Dubois, O., Walking the Nexus Talk: Assessing the Water-Energy-Food Nexus in the Context of the Sustainable Energy for All Initiative, Climate, Energy and Tenure Division (NRC), Food and Agriculture Organization of the United Nations (FAO), 2014.

[3] Chhipi-Shrestha, G., Hewage, K. \& Sadiq, R., Water-Energy-Carbon nexus modelling for an urban water system: A system dynamics approach. Journal of Water Resources Planning and Management, 143(6), 2017.

[4] Gonçalves, P., Water consumption in university buildings: A case study of the DECivil building of the University of Aveiro. MSc thesis, University of Aveiro, Portugal (in Portuguese), 2014.

[5] Meireles, I.C., Gonçalves, P., Sousa, V. \& Silva-Afonso, A., Water efficiency potential in university buildings: The DECivil building of the University of Aveiro. Proceedings of the 40th IAHS World Congress on Housing, pp. 16-19, 2014.

[6] Meireles, I., Sousa, V., Adeyeye, K. \& Silva-Afonso, A., User preferences and water use savings owing to washbasin taps retrofit: A case study of the DECivil building of the University of Aveiro. Environmental Science and Pollution Research, 2017. DOI: 10.1007/s11356-017-8897-5. 